\title{
A VOZ DA EVASÃO
}

\author{
Sheyla Fredenhagem ${ }^{1}$; Nilton Cometti'; Cristiane Jorge de Lima Bonfim'; Fernando Dantas \\ de Araújo ${ }^{1}$ \\ 'Instituto Federal de Educação, Ciência e Tecnologia de Brasília \\ sheyla.fredenhagem@ifb.edu.br - nilton.cometti@ifb.edu.br - cristiane.bonfim@etfbsb.edu.br - \\ fernando.araujo@ifb.edu.br
}

Artigo submetido em 16/08/2012 e aceito em 10/09/2012

\section{RESUMO}

O presente artigo traz como objeto de pesquisa a identificação dos motivos da evasão nos cursos ofertados pelo Instituto Federal de Brasília (IFB), durante o ano de 2010, cuja análise intenta constituir-se como parâmetro a subsidiar a elaboração da política de acesso e de permanência dos estudantes na escola, de conformidade com o Plano de Metas da Instituição, de forma a minimizar a vulnerabilidade que vitima parcela da sociedade e consolidar a inclusão, garantindo a formação profissional cidadã com êxito.
A evasão nos cursos do IFB em 2010 foi em média $37,9 \%$. O principal motivo alegado pelos consultados - incompatibilidade de horário do curso com as atividades diárias, como trabalho e outros - foi de $45 \%$.

PALAVRAS-CHAVE: evasão; causas; medidas pró-permanência; assistência estudantil.

\section{THE VOICE OF EVASION}

\section{ABSTRACT}

This paper presents a survey to identify the reasons for the evasion in the courses offered by the Instituto Federal de Brasilia (IFB) for the year 2010, whose analysis attempts to provide as parameter to subsidize the policy of access permanence of students in the school, in accordance with the objetives of the institution, to minimize the vulnerability that victims part of the society and consolidate the inclusion, ensuring citizen
The drop in the courses of the IFB in 2010 averaged $37.9 \%$. The main reason given by the consulted people was the incompatibility of the time course with daily activities like work and other, averaging $45 \%$. 
FREDENHAGEM; COMETTI; BONFIM; ARAÚJO (2012)

training successfully

KEY-WORDS: evasion; causes; measures pro-permanence; student assistance.

EIXO, v. 1, n. 2 


\section{A VOZ DA EVASÃO}

\section{INTRODUÇÃO}

A expansão da educação profissional no Brasil, a partir de 2003, implementou novas concepções e oportunidades de acesso a milhões de jovens e adultos da classe trabalhadora. Entretanto, enquanto a demanda por qualificação profissional está na casa dos oito milhões, a oferta de educação profissional brasileira ainda se limita a um milhão de vagas. A ampliação do acesso, conectada à permanência do estudante na escola, traz no seu bojo a necessidade de novas reflexões sobre o sistema de ensino, práticas pedagógicas, perfil do egresso, mas, principalmente, sobre a eficácia do sistema. A evasão aporta-se como um dos gargalos para a efetiva escolarização e qualificação desse nicho da população. Enquanto a educação profissional caminha no sentido de formar cidadãos integrais, completos, concomitantemente deve buscar atender aos objetivos estratégicos de igualdade política, econômica e social (PACHECO, 2011, p. 8). Para atender a esses objetivos, a escola há de preocupar-se, também, com os fatores que levam à retenção escolar, ao abandono dos cursos e aos impedimentos de continuidade no itinerário formativo. A evasão, portanto, abrange uma gama de causas que requerem entendimento para a melhoria tanto da eficiência quanto da eficácia do sistema. Entendemos eficácia aqui como a relação entre o número de matrículas efetuadas e o número de formados.

Nesse sentido, a Pró-Reitoria de Ensino do IFB houve por bem investigar possíveis causas da evasão escolar e organizar os indicadores observados, materializando-os em gráficos, num primeiro momento, com o intuito de, após proceder à leitura de todas as informações, efetivada a investigação, fundamentar a definição de um conjunto de medidas assistenciais, incluídas as de âmbitos pedagógico e psicológico, e outras de caráter social e geral, bem como curricular, em favor de soluções e/ou prevenção do desvio.

Essa perspectiva compunha o documento denominado Pró-Permanência, que estabelecia como meta precípua a implantação de programa de redução do índice de perda e do índice de alunos não concluintes nos campi, após apresentação dos resultados de avaliações qualitativas e quantitativas, concernentes à situação geral do IFB.

\section{METODOLOGIA}

Como ação primeira do Pró-Permanência, foi solicitado o envio de lista do nome e endereço eletrônico e/ou telefone dos alunos evadidos em 2010 às cinco unidades que compunham a estrutura multicampi do IFB. De posse desse material, procedeu-se ao contato com essas pessoas, com o intuito de manter com elas um elo direto, por meio do qual as causas da evasão fossem sentidas pré-reflexivamente, em todo o seu universo. Nessa perspectiva, remetemos a mensagem abaixo aos alunos cujos endereços eletrônicos nos foram enviados.

A Pró- Reitoria de Ensino do Instituto Federal de Brasília está fazendo um 
levantamento de alunos que desistiram do Curso, em 2010, com o intuito de buscar os motivos, de forma que possamos aprimorar todas as ofertas de cursos. Solicitamos a gentileza de nos informar as razões que o (a) levaram à desistência do curso (nome do Curso/Campus). Agradecemos sua atenção.

As mensagens recebidas dos alunos, justificando sua desistência, foram respondidas pela Pró-Reitoria de Ensino, individualizadas as abordagens, de forma a minimizar a distância entre o IFB e o aluno evadido, para que este não representasse e não fosse, de fato, figura anônima nesse processo. Nem todos nos deram retorno. Somando os contatos via e-mail e via telefone, de 974 casos de evasão referentes a 2010, abrangendo as diversas modalidades, cursos e campi, foram ouvidos 282 alunos, parcela correspondente ao percentual de $28,95 \%$. Embora a não totalidade, a parcela com que tivemos contato consegue mostrar a gama de problemas velados que sustentam a exclusão, leitura que supera a objetividade de dados apenas numéricos, salvaguardados, logicamente, no seu patamar de importância para tomadas de decisão.

Quanto ao contato via telefone, certa dificuldade se apresentou, quer pelo fato de muitos alunos não terem sido encontrados no momento da ligação, quer por ser, pela própria natureza, trabalho moroso, quer muitos telefones fixos serem de terceiros e isso ter constituído ruído na comunicação, quer muitos números serem de celular, fato dificultador. De qualquer forma, os contatos mantidos nos confirmaram o universo mencionado, ou seja, a existência de verdadeiros dramas de que não nos damos conta. É a "voz" da evasão na linha. Muitos chegam a adotar uma fala quase intimista. Daí esse canal suplantar o sentido dos números.

\section{RESULTADOS E DISCUSSÃO}

Do universo de 2564 alunos matriculados em 2010 no IFB, 974 evadiram, o que representou um percentual de $37,9 \%$ (Tabela 1), variando de 40 a $48 \%$ nos campi mais novos e $18,8 \%$ no Campus Planaltina, com origem na antiga Escola Agrícola de Planaltina. Esse campus já conta com a maioria dos cursos integrados, que possuem evasão menor do que os demais cursos. Muitos dos alunos usufruem de residência estudantil e todos dispõem de refeitório, que contribui para reduzir o nível de evasão.

Segundo Machado (2012), são praticamente inexistentes os estudos sobre a evasão na Educação Profissional no Brasil. Isso nos leva a crer que em nível nacional a situação não seja muito diferente da apresentada aqui. Relatos nos colocam níveis acima de $50 \%$ em alguns cursos, algo muito preocupante e que merece ações consistentes para reverter o quadro. Silva (2011) relata níveis de evasão em cursos técnicos integrados no IFBA de 5 a 15\%. Por outro lado, Silva \& Morgado (2006) relatam evasão média de $58 \%$ dos matriculados nos cursos do CEFETMG. Esses dados mostram uma crítica realidade que deve ser aprofundada no sentido de reverter o processo de evasão. 
FREDENHAGEM; COMETTI; BONFIM; ARAÚJO (2012)

Tabela 1. Dados gerais de matrícula, evasão e alunos evadidos consultados.

Motivos da evasão

Campi

Brasília Gama Planaltina Samambaia Taguatinga Total

Total de matrículas

Total de casos de

evasão

Total de alunos

evadidos consultados

(via e-mail/telefone)

Percentual de evasão

(\%)

Percentual de consulta

(\%)

$\begin{array}{llllll}\underline{395} & \underline{264} & \underline{740} & \underline{373} & \underline{792} & \underline{2564} \\ 161 & \underline{117} & \underline{139} & \underline{179} & \underline{378} & \underline{974}\end{array}$

$\begin{array}{llllll}\underline{38} & \underline{70} & \underline{18} & \underline{65} & \underline{91} & \underline{282}\end{array}$

$\begin{array}{llllll}\underline{40,7} & \underline{44,3} & \underline{18,8} & \underline{47,9} & \underline{47,7} & \underline{37,9} \\ \underline{23,6} & \underline{59,8} & \underline{12,9} & \underline{36,3} & \underline{24,1} & \underline{28,9}\end{array}$

Os motivos de evasão alegados pelas pessoas consultadas por campus são apresentados na Tabela 2. Os percentuais se mantêm próximos nos diversos campi, mostrando consistência nos resultados da pesquisa. Em função disso, preferimos discutir os dados agrupados, como apresentados na Figura 1.

Tabela 2. Motivos da evasão relatados pelos alunos evadidos consultados.

Motivos da evasão

$\underline{\text { Campi }}$

Brasília Gama Planaltina Samambaia Taguatinga Média

Incompatibilidade com

horário de trabalho

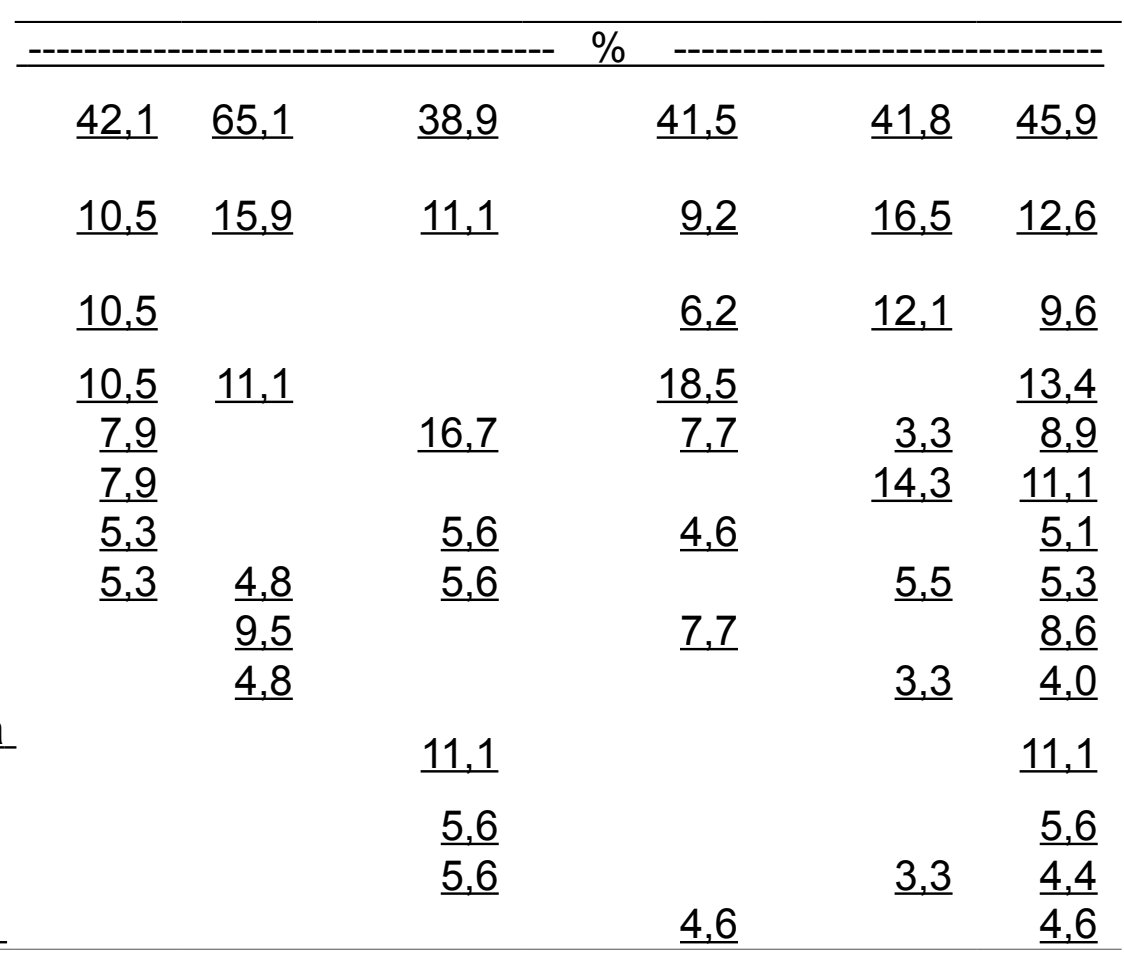

Incompatibilidade com

horário de outro curso

Expectativas não

atendidas

Outros

Problemas pessoais

Segurança

Distância

Saúde

Problemas financeiros

Mudança

Não se identificou com a

visão do curso

Transporte

Pré-requisito

Já possui conhecimento

EIXO, v. 1, n. 2 
FREDENHAGEM; COMETTI; BONFIM; ARAÚJO (2012)

$\underline{\text { da área }}$

No agrupamento geral dos dados dos vários cursos do IFB e no agrupamento das causas da evasão, os dados percentuais obtidos são mostrados na Figura 1. A principal causa, compondo $45 \%$ do total dos entrevistados, foi a incompatibilidade do horário do curso com o horário de trabalho. Uma outra parcela também importante, $13,5 \%$ de evasão, foi atribuída à incompatibilidade de horário dos estudantes com outros cursos em que estavam matriculados. Essas duas fontes demarcam 58,5\% de evasão, mostrando a importância da adequação dos horários de aulas para a permanência do aluno, mas que vêm acompanhadas de outras questões também intrínsecas à situação do aluno, como será mostrado nos seus vários relatos. Em terceiro plano, $6 \%$ dos entrevistados declaram não ter suas expectativas atendidas por diversas razões que descrevemos adiante. Outras razões, como problemas familiares, problemas financeiros e de saúde, não identificação com o curso, falta de segurança, distância da escola e o fato de já possuir conhecimento na área, registraram percentuais menores do que $5 \%$, mas que, em conjunto, compuseram em torno de $32 \%$.

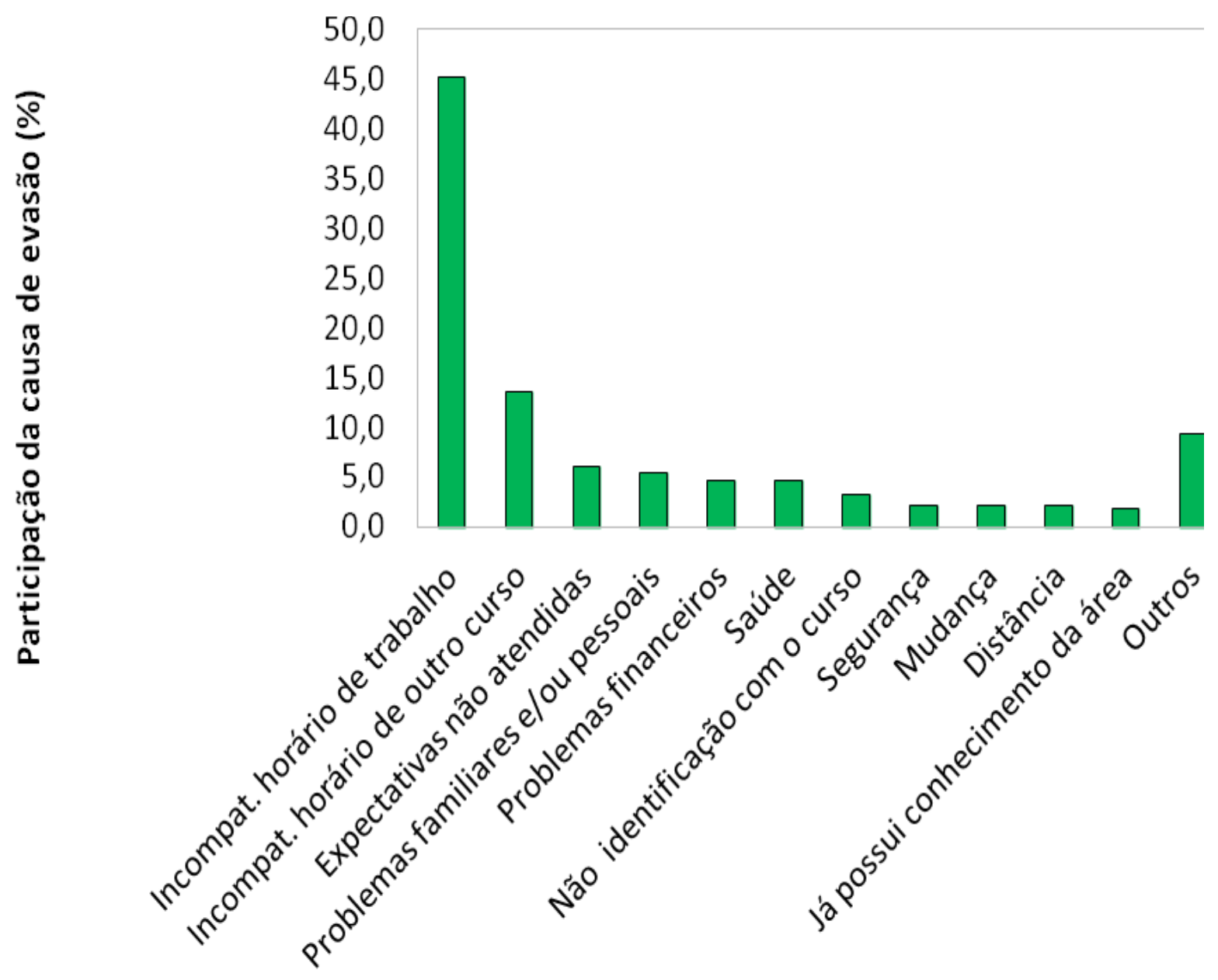

Causas da evasão

Figura 1. Percentual das causas de evasão de alunos dos cursos do Instituto Federal de Brasília. 
Conquanto os dados da evasão tenham sido inseridos em grupos temáticos representantes da causa primária que originou a desistência, consolidando, assim, objetivamente, um panorama das grandes áreas de concentração de problemas, a análise subjetiva desses dados, vistos isoladamente, é necessária e pertinente, pois trata-se de indicadores precisos para tomadas de medidas futuras, principalmente no tocante à Assistência Estudantil do IFB, cuja política visa promover condições de permanência e de apoio, por meio de programas, a estudantes sob vulnerabilidade social. Com o intuito de ilustrar essa justificativa, particularizando o tema financeiro, como base subjacente dos problemas desse grupo, obtêm-se nuances que requerem decisões diferentes. Há alegações textuais, como passe escolar, desemprego, assim como há razões veladas, deduzidas apenas por meio de uma análise mais subjetiva do conjunto de afirmações, que, embora originárias do mesmo motivo, requerem soluções diferentes, como é o caso de condições físicas, cansaço. O contexto em que foram ditas nos leva a crer que a oferta de alimentação no campus poderia contribuir para amenizar o problema, assim como a diversificação de horários associados à oferta campus/cursos, visando atender à proximidade da residência do maior número de pessoas. Resumidamente, passe escolar, desemprego, condições físicas, cansaço, desencadeadas, estas duas últimas causas, muitas vezes pela rotina de trabalho, poderiam ser computadas em grupos de ordem financeira; alguns entrevistados, porém, veem pela ótica do problema pessoal, tomando apenas para si a possibilidade futura de solução. Entretanto, qualquer que seja a forma de classificação, quando são particularizadas, essas causas requerem medidas diferentes por parte da instituição, conforme nos indicam algumas falas:

Informante 1 - Eu tinha passagem dada pelo governo para pegar o circular. Quando o curso terminava, o último circular já tinha passado. Eu era obrigada a pegar outro ônibus, e eu não tinha dinheiro.

Informante 2 - Distância da residência. Cansaço. Trabalho.

Informante 3 - Estava desempregado. Problemas financeiros. Não tinha dinheiro para a passagem.

Informante 4 - Dificuldades; não tinha passe estudantil.

Ainda enquadrados no âmbito financeiro, aparece no levantamento compra de livro, impossibilidade de imprimir material por não ter internet e não ter dinheiro para fazê-lo fora, dentre outras dificuldades, as quais poderão, doravante, ser sanadas por meio da Assistência Estudantil. $O$ transporte configura-se como fundamental para a permanência de um aluno em vulnerabilidade social, tanto pela oferta do passe escolar quanto pela disponibilidade de horários de ônibus.

Há um leque de causas secundárias que se desdobram em cadeia, dificultando a identificação da raiz do problema. Muitas vezes a alegação incompatibilidade de horário de trabalho tem suas raízes no problema relacionado ao trânsito caótico, escassez de ônibus, dentre outros entraves.

Informante 1 - Trabalho como cobrador de ônibus. Larguei o curso, porque eu chegava muito atrasado por causa do engarrafamento. 


\section{FREDENHAGEM; COMETTI; BONFIM; ARAÚJO (2012)}

Informante 2 - Distância. Dependia de duas conduções. Não tinha dinheiro para as passagens.

Informante 3 - Problemas com o horário de trabalho. Sempre chegava atrasado para as aulas. Cansaço, transporte. Chegava em casa mais de meia-noite.

É possível inferir que a dificuldade financeira e os problemas com transporte/trânsito implicam sérios entraves aos alunos, constituindo, especificamente, causas diretas de falta de alimentação, cansaço - carência que origina, em cadeia, outros problemas, inclusive de aprendizagem e de dificuldade de acompanhar o curso, culminando na evasão. Nem sempre eles têm clareza sobre a origem do problema e alegam, de imediato, dificuldade de conciliar o curso com o horário do trabalho. Somente no transcorrer da conversa é que o conjunto de dificuldades vai sendo exposto.

De 125 casos de desistência do curso relacionados a trabalho, cerca de $12 \%$ diz respeito à questão de escala de trabalho, alteração de turno, plantão.

Informante 1 - Infelizmente não tive condições de dar continuidade ao curso, pois minha escala de serviço foi alterada, ficando assim incompatível com o horário do curso. O curso e a professora são excelentes, de altíssimo nível.

Informante 2 - Trabalho por escala. Faço plantão em horário diversificado.

Informante 3 - Houve troca de turno no trabalho.

Ainda classificada nesse levantamento como incompatibilidade com o horário de trabalho, é digna de nota a verificação de que grande número de alunos desistiram do curso em função de terem arrumado um emprego e/ou tido resposta afirmativa de emprego no qual já haviam investido, anteriormente ao início das aulas. Tão logo foram chamados ao emprego, desistiram do curso. Conclui-se, pela reincidência de depoimentos afins, que muitos se inscreveram apenas por estarem ociosos naquele momento, mas conscientes de que o largariam a qualquer momento. A condição social, nesse caso, é preponderante, pois a vulnerabilidade social leva à necessidade de solução imediata da situação financeira. Isso nos remete à necessidade de adequação da escola ao cidadão, e não ao inverso. A escola deve ser vista como um bem público, à disposição da sociedade majoritariamente excluída.

A justificativa de alguns entrevistados nos leva a crer que a facilidade de acesso aos cursos faz com que arrisquem em grande parte das vezes, mesmo visualizando que correrão o risco de ter de abandonar o curso no meio do caminho. Simplesmente arriscam. Essa situação traz, sem dúvida, alguns aspectos positivos, porém também pode significar perda para pessoas que tenham objetivos claros e meta programada para irem até o fim e que tiveram sua vaga ocupada. A entrevista prévia, dentre outros fins, oportuniza aumentar a chance de pessoas que realmente intencionam concluir o curso.

Informante 1 - Queria fazer uma experiência. O curso não tinha nada a ver com o meu perfil.

Informante 2 - Comecei a fazer curso pré-vestibular no horário do curso. 


\section{FREDENHAGEM; COMETTI; BONFIM; ARAÚJO (2012)}

Informante 3 - Comecei a trabalhar no horário do curso.

Em contraposição, o arriscar abre novas oportunidades ao educando. A possibilidade de inserção na escola pode representar a continuidade, mesmo que mudando de curso, e a possibilidade de formação antes tão distante do cidadão. O ingresso por sorteio permite que isso seja possível, mesmo diante de tantos desafios, o que não pode ocorrer em outras formas de ingresso excludentes. Os Institutos Federais inovam ao trilhar essas experiências que vêm sendo ampliadas. Cotas para oriundos da escola pública e afrodescendentes, sorteio etc. são iniciativas que podem e devem ser implementadas (PACHECO, 2011, p. 12).

A expectativa relacionada à possibilidade de haver ofertas diversificadas, associadas à repetição de cursos no mesmo Campus e em outros, cobrindo as várias regiões e horários, reitera-se em muitas falas.

Informante 1 - Gostaria que tivesse em Taguatinga alguns cursos que há em outros polos.

Informante 2 - Se surgir o mesmo curso na Asa Norte, se possível for, gostaria do contato de vocês. Obrigada.

Informante 3 - Tenho uma sugestão. O IFB poderia abrir cursos nos finais de semana pelo motivo de muitas pessoas trabalharem e ter tempo apenas nos finais de semana.

Informante 4 - Infelizmente tive que desistir do curso pois iniciei um novo emprego de período integral e o instituto não oferecia o curso à noite.

Informante 5 -_Acho que se houvesse uma turma no período matutino, certamente eu não teria desistido.

Informante 6 - Obrigada pelo contato, espero que o IFB insira cursos de graduação e pós-graduação em Taguatinga e Samambaia em breve.

Informante 7 - Gostaria que houvesse turmas no sábado de manhã ou no domingo, pois tenho interesse em fazer outros cursos também.

Novamente a necessidade de adequação da escola à vida do aluno. A fala "turmas no sábado de manhã ou no domingo" mostra a predisposição de sacrifício do final de semana em prol da qualificação, mas que deve ser acompanhada pela Instituição. Isso implica sair da "zona de conforto" em busca do atendimento das demandas da sociedade.

Dos 14 itens inseridos no segmento problemas familiares e/ou pessoais, compõem esse rol de motivos 06 casos relacionados à questão de Gênero, pelo fato de incluir mulheres em fase de terem filhos pequenos e não terem com quem deixá-los, ou em fase de gravidez.

Informante 1 - Eu não tinha com quem deixar meu filho de dois anos e engravidei novamente.

Informante 2 - Desisti para cuidar das minhas filhas. Eu não tinha com quem deixá-las.

Informante 3 - Engravidei e não tive condições de continuar o curso.

Informante 4 - Não tinha quem cuidasse do meu filho de dois anos, no

EIXO, v. 1, n. 2 


\section{FREDENHAGEM; COMETTI; BONFIM; ARAÚJO (2012)}

horário do curso.

Informante 5 - Problemas particulares. Para cuidar das minhas filhas.

Cabe ressaltar que, embora categorizados como pessoais, conforme dizeres das próprias entrevistadas antes de entrarem no mérito da causa específica, a discussão sobre Gênero extrapola as paredes particulares, familiares, caracterizando-se, na atualidade, como fenômeno de cunho social. Oliveira (2010) afirma que:

Felizmente, qualquer elemento coletivo só pode ser vislumbrado pelo particular - mediador precário, movente e fugaz. Não se consegue estudar um grupo a não ser pelos indivíduos que o compõem, não se consegue estudar uma língua sem a mediação do uso que nasce de alguém, em um contexto, em um tempo. Só se consegue estudar literatura pela mediação da obra. É por isso que o conhecimento não se esgota". (OLIVEIRA, 2010, p.35)

Os problemas de ordem social diversificam-se, chegando ao âmbito da segurança.

Informante 1 - Segurança. Eu voltava tarde para casa.

Informante 2 - Fui assaltado na saída do curso. Não quis ir mais.

Informante 3 - Insegurança (assalto em ônibus).

Informante 4 - O curso terminava muito tarde...E eu não tinha com quem voltar para casa.

Uma questão que envolve, diretamente, o corpo docente, levantada por alunos de cursos de Formação Inicial e Continuada, está relacionada ao tratamento do adulto, especificamente no tocante à necessidade de intervenção do professor, considerando o longo período durante o qual o aluno esteve afastado dos bancos escolares. As suas limitações dizem respeito a condições diversas, que vão desde a dificuldade de aprendizagem até dificuldade de escrita, como limites para acompanhar o ritmo do professor, para copiar a escrita feita nos quadros em tempo hábil, outros, inclusive limitações físicas e problemas relacionados à alfabetização:

Informante 1 - Não sei ler direito. Por isso não consegui acompanhar o curso.

Informante 2 - Eu não aguentava ficar sentada durante muito tempo.

Informante 3 - Tenho 27 anos de profissão. Saí do curso porque percebi que já sabia tudo o que estava sendo ensinado. Não achei justo ocupar a vaga de outra pessoa. Estou aguardando a certificação. Pela dificuldade de escrita, só solicito que os quadros não sejam apagados rapidamente, porque às vezes não conseguimos acompanhar. Não somos como adolescentes que escrevem rápido. (Ainda por telefone mencionou a dificuldade de segurar a caneta em função de problema ocasionado nos dedos pelo trabalho que exerce há muitos anos).

Também foram motivos de desistência problemas relacionados à estrutura física do IFB, lacuna que implicou, provavelmente, queda da qualidade de alguns cursos ofertados e, indiretamente, da ação docente, pois, pelos depoimentos, foi fator de 
interferência em todo processo didático-pedagógico. Essa questão, oriunda da pesquisa, diz respeito à estrutura do curso. Trata-se, num primeiro momento, da falta de equipamento e de espaço físico adequado.

A expansão da Rede de Educação Profissional e Tecnológica traz, intrinsecamente, urgência de atendimento à grande massa de pessoas excluídas, que necessitam de qualificação imediata. Isso leva à prática de abertura de cursos em concomitância com a preparação da infraestrutura de laboratórios e de contratação de pessoal para atendimento à demanda. Disso deriva uma nova necessidade, a de capacitação do corpo docente e técnico em assuntos educacionais, criando-se um ciclo de demandas.

O Instituto Federal de Educação, Ciência e Tecnologia de Brasília foi criado em 29 de dezembro de 2008, nos termos da Lei $n^{011.892 . ~ S u a s ~ a t i v i d a d e s ~ i n i c i a r a m-s e ~ e m ~}$ 2009, portanto dois anos antes da pesquisa em pauta. Embora pareça prematura a realização de uma pesquisa desta natureza, tendo em vista não apenas o pouco tempo de atuação do IFB, mas também pelo fato de alguns campi pesquisados estarem funcionando em instalações provisórias, por ocasião das entrevistas, não foi assim considerada. Pelo contrário, viu-se premência, pois o intuito era, justamente, o de levantar toda ordem de dificuldades apresentadas pelos alunos da região, de forma a estruturar o IFB e futuros campi sob parâmetros reais, dentro de padrões de atendimento satisfatório, já consolidando uma cultura de avaliação permanente no Instituto. Por outro lado, também dispor de elementos seguros para a implementação da Assistência Estudantil.

Nessa perspectiva, foram trazidos à tona todos os indicadores da evasão ocorrida em 2010. Há de se destacarem as queixas - legítimas, diga-se de passagem referentes a condições ambientais, principalmente, nas quais se inserem as aulas práticas. Essas queixas destacaram-se, especificamente, em dois cursos, demonstrando a necessidade de aulas práticas, devido à índole dos cursos de Formação Inicial e Continuada - FIC, direcionados à qualificação profissional, em todos os níveis de escolaridade, conforme Decreto $n^{\circ} 5.154$ de 23 de julho de 2004, os quais demandam muitas atividades práticas e permeiam-se pelo "fazer para aprender". Isso diferencia os cursos FIC, distanciando-os do academicismo e aproximando-os da educação profissional e tecnológica dos Institutos Federais.

Algumas falas refletem essa realidade:

Informante 1 - Falta de equipamento para todos os alunos nas aulas práticas.

Informante 2 - Havia poucas pessoas no curso. Fiquei desestimulado. 0 professor se esforçava mas as salas não eram boas e havia problema de planejamento, porque não havia organização prévia dos equipamentos. Isso atrasava a aula. O curso era interessante, as discussões eram legais, mas as condições não eram boas.

Informante 3 - Só tinha teoria. Faltava a prática. O curso em si não correspondia com a minha expectativa. Havia mais de vinte alunos numa sala pequena e apertada que nem janela tinha. Não tinha como sentar direito. Assim não dava para aprender.

As condições físicas do ambiente somam-se à carência de aulas práticas, ocasionando a evasão, como se observa no último depoimento.

EIXO, v. 1, n. 2 


\section{FREDENHAGEM; COMETTI; BONFIM; ARAÚJO (2012)}

As razões, equivocadas ou não, misturam-se na fala dos entrevistados, ao queixarem-se, também, da estrutura do curso, adentrando o âmbito da comunicação.

Informante 1 - Pensei que era uma coisa. Quando cheguei era outra. Pensei que era aula prática e só era teoria.

Informante 2 - O curso não estava interessante. Conteúdo longe da realidade, com pouca aplicabilidade prática. O curso estava fora de foco.

Há crítica acentuada referente à ausência de orientações prévias sobre o que viria a ser o curso. Vem à tona a emergência de ações consistentes e pontuais no tocante à divulgação das ofertas e informações a respeito da pertinência da área de conhecimento, de forma a não frustrar as expectativas dos alunos.

Informante 1 - Senti falta de informações prévias sobre o curso.

Informante 2 - Quando chegou no meio do curso vi que não era a área que eu queria.

A falta de conhecimento prévio do curso pelo aluno, tanto do curso técnico, quanto do superior e de formação inicial e continuada, foi detectada nesta pesquisa como uma fonte importante de evasões, que podem ser sanadas com palestras prévias ao processo de inscrição do candidato, mostrando a área de atuação do profissional, de forma a orientar o posicionamento do aluno frente às possibilidades no mundo do trabalho.

Embora os estudantes tragam do senso comum noção formulada a partir do nome do curso, não raro demonstram que não Ihes são claras as suas abordagens e campo de atuação.

Informante 1 - Pela ausência de ementa do curso, as expectativas do que seria o curso não corresponderam. O professor era excelente, sua metodologia também, mas o curso não era o que eu esperava. Pensei que se tratava de outro curso. Senti falta de informações prévias sobre o curso.

Informante 2 - Eu desisti porque não estava correspondendo às minhas expectativas. Estava achando muito fora do meu objetivo.

Informante 3 - O curso não era como queria.

Informante 4 - Achei que o curso fosse voltado para a área administrativa.

Informante 5 - Pensei que era outra coisa.

Informante 6 - Não me identifiquei com a visão do curso, que era voltado para o lado ecológico e não de uma nova ciência (produção de alimentos, conservação da natureza). Havia uma série de definições com que não concordava.

Informante 7 - Não estava claro o que seria o curso. A proposta não era boa. O curso não gerou expectativa.

Informante 8 - Pensei que fosse curso de instrumento. O curso era de musicalização.

Essas falas ratificam a importância do planejamento dos cursos, com planos bem

EIXO, v. 1, n. 2 


\section{FREDENHAGEM; COMETTI; BONFIM; ARAÚJO (2012)}

delineados, contendo, além da estratégia, equipamento pedagógico que dê consistência ao curso e segurança ao aluno. Esse pressuposto estende-se aos cursos FIC, guardadas as devidas proporções com os cursos técnicos e superiores.

Cabe registrar, como experiência única, gratificante, o contato direto com pessoas, quase anônimas, mas representativas do campo de trabalho do IFB, que buscam a esperança da qual o IFB é o protagonista. Por meio do fio do telefone veem-se dramas pessoais; tem-se a ideia clara das dificuldades diversas, da barreira que se interpõe entre muitos cidadãos e a escola, no seu sentido genérico, ou, por que não dizer - uma possível porta de ascensão. Tem-se, na verdade, contato com dramas pessoais que impedem e/ou dificultam sobremaneira o acesso dessas pessoas. Muitas vezes o contato foi feito com familiar, normalmente pais, os quais, quase confidencialmente, deixavam transparecer o orgulho de ter um filho que frequentou um curso, mesmo que durante poucos dias ou meses, ao mesmo tempo que expressavam o lamento do abandono, 0 qual logo era substituído pela esperança, que reascendia ante a possibilidade de novas oportunidades por nós informadas. Nesse universo, que nem imaginamos existir, sempre há, implicitamente ou não, um pedido de orientação, de ajuda... um desabafo. Quantas lutas caladas!

Informante 1 - Acho que perdi mais uma chance. Por favor me ajude. Informante 2 - Gostaria muito de continuar...mas não sei se é possível!

E quantas incógnitas sob o véu de respostas lacônicas:"Falta de dinheiro", ou ainda, "Problemas pessoais".

O que esse telefonema representou na vida de quem o recebeu? Inevitavelmente nos perguntamos. Retornou aos estudos? O contato estimulou essa decisão ou outra? Essa reflexão nos faz lembrar de três momentos, no mínimo, curiosos. Numa oportunidade, a pessoa que atendeu (voz feminina) afirmou, num primeiro impulso, que o aluno evadido havia morrido. Disse isso de forma agressiva. Em seguida falou que ia passar o telefone para ele. $O$ aluno atendeu pedindo desculpas e disse que era a "mulher" dele. Num outro caso, uma mãe pediu que, quando descobríssemos por que o filho abandonou o curso, fizéssemos a gentileza de avisá-la, pois também queria saber. Num terceiro caso, fomos atendidos por uma voz masculina, bastante ríspida quando mencionamos o nome da aluna evadida perguntando se era de sua residência. Não respondeu e, parece-nos, desligou o telefone. Como essa atitude não nos ficou clara, tentamos novamente. A própria aluna atendeu e disse, entre dentes, que deixou o curso, já na metade do terceiro semestre, por "problemas pessoais". Não quis prolongar o assunto. Desligou o telefone.

Independentemente de obtermos respostas sobre os motivos da desistência, que poderiam ser por amostragem, a quantidade de entrevistas também se faz importante, pois é um momento oportuno de personalizar o tratamento ao aluno, que, muitas vezes, declara que vai retornar à Instituição, exatamente por perceber, com o nosso contato, interesse por ele. Fica evidente a possibilidade de retorno desse aluno ou, poderíamos dizer, de resgate de uma pessoa que, talvez, nunca mais sentasse num banco escolar.

Parte significativa de alunos demonstrou receptividade ante a iniciativa tomada pelo IFB de convocá-los a falar dos motivos de sua desistência. Ao mesmo tempo mostravam-se surpresos por já terem dado por perdidas as suas oportunidades e, com a nossa procura, sentirem-se diante da chance de refazer o curso e/ou fazer novos cursos 
em curto prazo. Essa reação, que pode significar nova postura frente à evasão, dá-nos uma pista dos resultados que poderão surgir em tempo breve, conformados nos quadros estatísticos, nos próximos anos. É notório que os alunos têm se mostrado preocupados com sua decisão de evadir-se, assumindo o esforço de retorno como compromisso futuro. Vários indícios contribuem com a perspectiva de mudança cultural do corpo discente, no sentido de não agir com descaso para com o ensino público, muito menos transferir sua parte de responsabilidade, isentando-se de qualquer compromisso para com a escola e para consigo mesmo.

Informante 1 - Se pode me dar mais uma oportunidade abraçarei com todas as minhas forças.

Informante 2 - Peço se possível a compreensão quanto ao meu problema e se possível em outra oportunidade me dar uma nova oportunidade.

Informante 3 - Gostaria de saber se haverá novas turmas.

Informante 4 - Grato pela oportunidade e meu pedido de desculpa à instituição (pela desistência).

Informante 5 - Pena que não posso mais ir. Um abraço. Fique com Deus.

Informante 6 - Obrigado por se lembrar de mim.

Informante 7 - Muito obrigado pela preocupação.

Postura de agradecimento, de contribuição, de esperança, de solidariedade para com a pesquisa, de animação pelo tratamento dispensado à educação foi o clima encontrado na maioria dos contatos. Essa ambiência, associada ao uso de palavras incentivadoras, nos faz lembrar que "vale a pena".

Informante 1 - Fico feliz pela atenção que estão tendo para com os alunos, isso nos mostra que estamos num país que está cada vez mais com profissionais preocupados com a educação. Parabéns.

Informante 2 - Espero ter ajudado de alguma forma.

Informante 3 - Estou à disposição para mais esclarecimentos.

Informante 4 - Agradeço a gentileza e fico à disposição. Abraços.

Informante 5 - Obrigado por tudo.

Informante 6 - Fico feliz pelo contato.

Informante 7 - Agradeço pela atenção.

Informante 8 - Agradeço ao professor e equipe pelo trabalho e parabenizo pela atitude da proposta do Instituto.

Presume-se que o acompanhamento do egresso também nos levará a esse retorno, considerando ser função da escola manter-se conectada com o mundo do trabalho, incluindo-se as pessoas trabalhadoras provenientes da instituição. 


\section{PROPOSTAS DE MEDIDA E FOMENTO}

Considerando sua responsabilidade social, é possível visualizar o grande desafio do IFB no que tange à promoção de ações que interfiram nesses problemas, relacionados, comumente, a fatores externos. Embora assim vistos culturalmente, a questão é: ocasionam evasão.

Trazer o aluno desistente à presença da Pró-Reitoria de Ensino constituiu passo decisivo para que um volume de casos de evasão não venham a acumular-se ano após ano. O processo de escuta não apenas subsidiou a interpretação dos dados coletados como também incitou o estudo de procedimentos visando conter reiterações futuras e apontou a necessidade de observação periódica e de acompanhamento de desistências que venham a ocorrer, considerando que, dirimidas as causas ora levantadas, outras poderão surgir, em novos contextos, requisitando novas intervenções, senão estas.

Nesse sentido, urge instituir-se um conjunto de procedimentos rotineiros, sob avaliação permanente, fundamentados nas pesquisas feitas, que levem em conta e observem três momentos distintos: a fase anterior à entrada do aluno, a fase durante sua permanência e a fase posterior, na condição de egresso.

\section{FASE ANTERIOR À ENTRADA DO ALUNO}

Fomento de ações de divulgação dos cursos em escolas de Ensino Fundamental e Médio, públicas e privadas, visando a, prioritariamente, informar o ingressante sobre todas as características do curso, orientá-lo sobre os itinerários possíveis, mercado de trabalho e pré-requisitos, porém também com o intuito de divulgar o IFB e Cursos, bem como obter uma prévia de interesse da comunidade. Em linguagem acessível, essa divulgação, a exemplo de alguns formatos já existentes, prevê palestras, fôlderes contendo informes sobre o que é o curso, conhecimentos prévios para acompanhá-lo, condições de empregabilidade previstas que 0 aluno terá quando concluí-lo, oportunidades que o mercado de trabalho de Brasília oferece, bem como o mundo do trabalho, de forma genérica, e outras informações pertinentes.

Somam-se a essas ações todas as medidas deliberadas para o processo de ingresso, com especial atenção às palestras orientativas obrigatórias para todos os candidatos, visando colocá-los em contato com a realidade do curso.

\section{FASE DURANTE À ENTRADA DO ALUNO}

Fomento de discussões em cada campus em busca da compreensão das causas de evasão para tomada de decisão sobre providências imediatas, por meio de ações pontuais pró-permanência, considerando características pautadas nos cursos oferecidos naquele campus, perfil dos alunos de cada habilitação/modalidade/nível e demais peculiaridades regionais e de ordem didático-pedagógica. Aqui vale destacar a importância de proporcionar a verticalização do itinerário formativo do aluno, permitindo que passe para outros níveis ao término de um curso, no próprio IFB. A verticalização também funciona como um incentivo à permanência do aluno no curso.

Acompanhamento, junto à Coordenação de Registros Acadêmicos, do 
controle de faltas, bem como possíveis causas registradas, em tempo imediato à ocorrência, para fins de medidas de prevenção a serem discutidas com a equipe de ensino, incluindo a sugestão a esse setor de convocar (procurar) os alunos em risco de evasão, via carta orientadora, telegrama, e-mail, telefone e/ou outros meios viáveis.

Fomento de adoção de parcerias com Faculdades da região, abrindo espaço a voluntários para ministrarem aulas de reforço, em horários extracurriculares, em casos de discrepância no tocante a pré-requisitos.

Fomento de convite a palestrantes da área e/ou profissionais ligados ao mundo do trabalho, oriundos do âmbito público e privado, objetivando incentivar o aluno a concluir o curso, bem como a visualizar itinerários profissionais possíveis a partir do curso.

Articulação de ações orientadoras aos servidores administrativos e professores, visando a acolher o aluno e estabelecer procedimentos comuns, coesos com a missão do Instituto.

Fomento de ações orientadoras e de divulgação do Instituto aos pais, de forma a colaborarem com a permanência de seus filhos e incentivarem a conclusão do curso.

Levantamento de vagas no mercado de trabalho disponíveis no ano em curso e no anterior, para divulgar ao aluno e proceder a projeções até o término do curso.

Orientação ao aluno mediante levantamentos de concursos públicos que requisitam profissionais cuja formação esteja vinculada ao eixo tecnológico do curso ao qual o aluno esteja vinculado, observando-se o Catálogo Nacional de Cursos Técnicos e o de Cursos Superiores de Tecnologia e a Classificação Brasileira de Ocupações - CBO.

Acompanhamento dos alunos cursistas por meio de entrevistas ou de outros recursos, visando manter os dirigentes do campus informados sobre:

(1) se o curso é o que o aluno esperava;

(2) as dificuldades sentidas pelo aluno (para que se estudem possíveis formas de reversão do problema);

(3) outras questões de ordem pessoal, incluindo a psicológica e emocional, e didático-pedagógica.

É possível afirmar que a comunicação mediada pela Assistência Estudantil entre professores e Coordenação de Registro Acadêmico, centralizando nesta última todo o fluxo de informações ao aluno, possa ser instituída por meio de um roteiro previamente estabelecido, que constitua um programa comum, sempre passível de adequações, funcionando sob esquema operacional que se torne prática da escola.

\section{FASE POSTERIOR À ENTRADA DO ALUNO}

Entrevistas a egressos, por meio da criação de um Banco de Dados, a fim de estabelecer com eles parceria, de forma a cooperarem com informações pertinentes ao curso de formação dirigidas aos cursistas, estendendo-lhes a possibilidade de atuarem como convidados palestrantes, bem como na condição de voluntários, conforme proposição já mencionada.

\section{CONCLUSÃO}

EIXO, v. 1, n. 2 


\section{FREDENHAGEM; COMETTI; BONFIM; ARAÚJO (2012)}

Fica a observação de que o esforço maior deva incidir no aluno que ainda está na escola. Em outras palavras, o investimento será de maior eficácia se as ações estiverem voltadas ao aluno que esteja frequentando o curso.

Embora o número de pessoas consultadas esteja aquém do ideal, as respostas obtidas elucidam e fundamentam os grupos de problemas que orientaram a proposição de medidas que têm a finalidade de evitar situações futuras vulneráveis.

O quadro da evasão aqui delineado aponta que, considerando a oferta para os cursos técnicos ser de 40 vagas por turma, equivaleria dizer que o índice de perda, em 2010, girou em torno de 24 turmas, se o grupo de 974 casos registrados nas listas enviadas pelos campi se tratasse apenas de alunos oriundos dessa modalidade.

Dentre problemas de várias ordens, constata-se, portanto, que esses estudantes trazem, de forma muito acentuada, carência básica, como alimentação (fruto de problemas financeiros), cansaço (poucas horas de sono/dificuldade de conciliar trabalho/estudo/distâncias/trânsito), os quais dão origem a outros problemas, como dificuldade de acompanhar o curso, desinteresse (gerados, por sua vez, pelo excesso de faltas) e outros mencionados, que formam, segundo nossa percepção, verdadeira cadeia de efeitos. Consequentemente culminam na evasão.

Reiteramos que, de acordo com a pesquisa aplicada, pudemos observar que cada grupo dos problemas apontados apresenta, não raro, uma causa-fonte, geradora de outros problemas causadores da evasão. De outra forma, é como se houvesse um núcleo, do qual emanam elementos periféricos. A Instituição atua no campo periférico, e não no núcleo ou tema gerador, ou causa-fonte, caso assim se queira entender. Não é papel do IFB oferecer um emprego, por exemplo, para o educando, mas minimizar, coibir efeitos indesejáveis da lacuna financeira ocasionada pelo desemprego, propiciando condições para a permanência do aluno na escola, como alimentação, passe estudantil, material escolar e outras medidas. Assim seria o raciocínio para demais situações, como trabalho. Esta causa-núcleo gera diversos efeitos periféricos, como trânsito, distância, cansaço e seus respectivos desdobramentos, em outros patamares de consequências, a exemplo de uma "bola de neve". Se não é da competência da instituição oferecer ao aluno um emprego, como já dissemos, tampouco é de sua responsabilidade oferecer-lhe moradia nas proximidades da escola. Com exceção das Agrotécnicas, que guardam a possibilidade de alojamentos. Como já discutimos, a variedade de ofertas de cursos, cobrindo várias regiões e períodos, somadas a outras providências atuam diretamente, não no núcleo, mas no campo periférico. Reside aí a responsabilidade social do Instituto.

Essa possível leitura ora apresentada pontua o amparo social ao estudante cuja situação socioeconômica requeira atenção por parte da Assistência Estudantil.

Entendemos que esse encaminhamento possa minimizar alguns efeitos das dificuldades vividas pelo estudante para se manter na escola, principalmente no que diz respeito ao aspecto financeiro. Alimentar-se no próprio campus, entre outros benefícios, eliminaria o ciclo que o expulsa da escola: o dispêndio de tempo no trânsito o impede de se alimentar em sua casa; por outro lado não tem dinheiro para se alimentar fora de casa...

Se, por um lado, os resultados apresentados mostram que o Instituto Federal de Brasília encontra-se no cumprimento de sua missão, por abrigar em seus campi grande parcela da classe social menos favorecida, por outro, pressupõe-se, há uma contrapartida a essa conquista: deflagra-se, então, a necessidade e compromisso de incluir na pauta da estrutura dos campi um efetivo trabalho social de sustentação e 
elevação cultural dessa demanda, que também representa grande parte da força de trabalho do país.

\section{REFERÊNCIAS}

MACHADO, Marcela, R.L. MOREIRA, Priscila R. Educação Profissional no Brasil, evasão escolar e transição para o mundo do trabalho. In: SEMINÁRIO NACIONAL DE EDUCAÇÃO PROFISSIONAL, 1., 2008, Belo Horizonte. Anais. Belo Horizonte: Faculdade de Educação - UFMG, $2008 . \quad$ Disponível em: http://www.senept.cefetmg.br/galerias/Arquivos_senept/anais/terca_tema3/TerxaTema3P oster9.pdf. Acesso em: 13 mai 2012.

OLIVEIRA, Fernanda Ribeiro Queiroz de. As santas quebradas: violência contra mulher pela voz das vítimas. Goiânia: Ed. Da PUC Goiás, 2010.

PACHECO, Eliezer. (Org). Institutos Federais: uma revolução na educação profissional e tecnológica. São Paulo: Moderna, 2011. 120 p.

SILVA, Wilney Fernando. Evasão Escolar nos cursos Técnicos Integrados do IFBA campus Eunápolis. In: ANPAE, 2011. Anais .... São Paulo: Anpae, 2011. Disponível em: http://www.anpae.org.br/simposio2011/cdrom2011/PDFs/trabalhosCompletos/comunicaco esRelatos/0548.pdf. Acesso em: 13 mai 2012.

SILVA, Ivo da; MORGADO, Maria Aparecida. Educação e juventude: evasão escolar no CEFET-MT após a reforma da educação profissional. In: Reunião Anual da SBPC, 58, 2006, Florianópolis. Resumos. Florianópolis, 2006. Disponível em: http://www.sbpcnet.org.br/livro/58ra/SENIOR/RESUMOS/resumo_2345.html. Acesso em: 13 mai 2012. 